\title{
Possible in-vessel corium progression way in the Unit 1 of Fukushima Dai-ichi nuclear power plant using a phenomenological analysis
}

\author{
Frédéric Payot ${ }^{1, *}$ and Jean-Marie Seiler ${ }^{2}$ \\ ${ }^{1}$ CEA Cadarache/DTN/SMTA/LPMA, 13108 Saint-Paul-lez-Durance cedex, France \\ ${ }^{2}$ CEA Grenoble/DTN/STCP/LTDA, 17, rue des Martyrs, 38054 Grenoble cedex 9, France
}

Received: 28 April 2015 / Received in final form: 7 July 2015 / Accepted: 15 September 2015 Published online: 05 December 2015

\begin{abstract}
In the field of severe accident, the description of corium progression events is mainly carried out by using integral calculation codes. However, these tools are usually based on bounding assumptions because of high complexity of phenomena. The limitations associated with bounding situations ([J.M. Seiler, B. Tourniaire, A phenomenological analysis of melt progression in the lower head of a pressurized water reactor, Nucl. Eng. Des. 268, 87 (2014)] e.g. steady state situations and instantaneous whole core relocation in the lower head) led CEA to develop an alternative approach in order to improve the phenomenological description of melt progression. The methodology used to describe the corium progression was designed to cover the accidental situations from the core meltdown to the molten core concrete interaction. This phenomenological approach is based on available data (including learnings from TMI2), on physical models and knowledge about the corium behavior. It provides emerging trends and best estimated intermediate situations. As different phenomena are unknown, but strongly coupled, uncertainties at large scale for the reactor application must be taken into account. Furthermore, the analysis is complicated by the fact that these configurations are most probably three dimensional, all the more so because 3D effects are expected to have significant consequences for the corium progression and the resulting vessel failure. Such an analysis of the in-vessel melt progression was carried out for the Unit 1 of the Fukushima Dai-ichi nuclear power plant. The core uncovering kinetics governs the core degradation and impacts the appearance of the first molten corium inside the core. The initial conditions used to carry out this analysis are based on available results derived from codes like MELCOR calculation code [R. Ganntt, D. Kalinich, J. Cardoni, J. Phillips, A. Goldmann, S. Pickering, M. Francis, K. Robb, L. Ott, D. Wang, C. Smith, S. St. Germain, D. Schwieder, S. Phelan, Fukushima Daiichi Accident Study (Status as of April 2012), Sandia Report Sand 20126173, Unlimited Release Printed August, 2012]. The core degradation could then follow different ways: axial progression of the debris and the molten fuel through the lower support plate; lateral progression of the molten fuel through the shroud. On the basis of the Bali program results [J.M. Bonnet, An integral model for the calculation of heat flux distribution in a pool with internal heat generation, in Nureth7 530 Conference Saratoga Springs, NY, USA, September 10-15, 1995 (1995)] and the TMI-2 accident observations [D.W. Ackers, J.R. Wolf, Relocation of Fuel Debris to the Lower Head of the TMI2 Reactor Vessel-A possible scenario, TMI 2 pressure vessel investigation project, in Proceedings of the Open forum OECD/NEA and USNRCm, Boston, USA, 20-22 October 1993 (1993)], this work is focused on the consequences of a lateral melt progression (not excluding an axial progression through the support plate). Analysis of the events and the associated time sequence will be detailed. Besides, this analysis identifies a number of issues. Random calculations and statistical analysis of the results could be performed with calculation codes such as LEONAR-PROCOR codes [R. Le Tellier, L. Saas, F. Payot, Phenomenological analyses of corium propagation in LWRs: the PROCOR software platform, in ERMSAR 2015, Marseille, France, 24-26 March, 2015 (2015)].
\end{abstract}

\footnotetext{
* e-mail: frederic.payot@cea.fr
} 


\section{Introduction}

The three accidents (i.e. accidents in Units 1, 2, and 3) led to different degrees of core damage, with Unit 1 being probably the most severely damaged of the three [1]. The first conjectures about the Unit 1 core damage assumed a vessel lower head failure, a core material release into the containment cavity, and core-concrete interactions likely initiated. Units 2 and 3 are likely less damaged $[2,3]$.

The description of corium progression events is mainly carried out by the mechanistic calculation codes. The safety demonstrations (e.g. AP1000 [4]) using these codes are usually based on bounding situations because of high complexity of phenomena. The limitations associated to bounding situations (e.g. problem of the focusing effect during the transient formation and steady state situations) led CEA [5] to develop, together with EDF, an alternative phenomenological approach (so-called "phenomenological approach") in order to supplement the current severe accident calculation codes [6].

The phenomenological approach developed in order to describe the corium progression covers the accidental situations from the core melting propagation down to the Molten Core Concrete Interaction (MCCI) in LWRs. This approach was elaborated from physical models and knowledge concerning the corium behavior, which provides emerging trends and plausible "best estimate" sequences. The analysis is complicated by the fact that phenomena are sometimes unknown and highly coupled at various scales. Moreover, these corium configurations in the lower head are most probably three dimensional, all the more so because local and non-axisymmetric effects are expected to have significant consequences for the vessel failure and corium release conditions into the reactor pit.

These last years, "phenomenological approach" studies were first concentrated on the French 1300 MWe PWR, considering both dry scenarios and the possibility of flooding of the primary circuit and/or the reactor pit. BWR reactors were also studied which provided the piece of information to analyze the in-vessel corium progression scenario in the Unit 1 of Fukushima Dai-ichi nuclear power plant.

Such an analysis of the in-vessel melt progression was carried out for the Unit 1 of the Fukushima Dai-ichi nuclear power plant. In the event timeline, the core uncovering velocity led to the core degradation of the Unit 1 . As an assumption, without additional water injection, the first core degradation events are the control rod liquefaction and downward relocation of the $\mathrm{B}_{4} \mathrm{C}$ and stainless steel, and fuel debris, in the lower core region. Then, the partial fuel melting could give rise to the appearance of the first corium pool in the centre of the core, as described by the MELCOR calculation code [2]. From that time, the core degradation scenario could follow different ways [7] according to the invessel melt progression, i.e.:

- axial progression of the debris and the molten fuel through the lower support plate and/or;

- lateral progression of the molten fuel through the shroud.

It is possible that both previous events did occur sequentially during the accident. In the following, we will develop the scenario based on lateral corium flow through the shroud.

The objective of this paper is to describe the alternative relocation path taking into account local and nonaxisymmetric effects. Several issues will be addressed such as the thermal loads on the shroud, the location and time delay to vessel failure and corium configuration in the lower head at vessel failure. Besides, this analysis identifies a number of open issues.

The models which have been derived from this analysis have recently been implemented in the PROCOR Platform [6], which is used for LWR reactor calculations. This calculation tool includes statistical evaluations (probability of occurrence, impact of uncertainties, and identification of most important parameters).

This work was presented in the frame of the OECD/ NEA/CSNI Benchmark Study of the Accident at the Fukushima Dai-ichi Nuclear Power Station (BSAF) project [8]. During 2012 and 2014 years, the purpose of this project was both to study, by mean of severe accident codes, the Fukushima accident in the three crippled units, until six days from the reactor shut-down and to give information about in particular the location and composition of core debris.

\section{Methodology}

The initial conditions used to carry out this analysis are based on partial core melting with an initial corium pool formed in the core. This core degradation state (e.g. amount, location, power, of melt corium pool, etc.) is described by existing codes, as for example, the MAAP and MELCOR calculation codes. The appearance of the first corium pool is strongly dependent on the kinetics of the core uncovery. During the Unit 1 damage sequence, available water levels in the core are not reliable. We will use data provided by the MELCOR calculation code [2].

Then the phenomenological evaluation is conducted step by step following the corium relocation path:

- in the core region:

- a new situation (compared to computational results) is carried out which corresponds to the kinetics of the melt corium growth, to the relocation in the space between core and shroud and to the ablation of shroud and of the core support plate. These phenomena depend on the presence of water, whose late injection conditions are also not well known;

- in the vessel lower part:

- evolution of the corium masses released into the vessel lower part, taking into account the occurrence of several corium flows at various time intervals;

- the formation of debris, the impact of focusing effect, the variations in the thermal loads and heating up of the vessel wall are evaluated in the presence of residual water;

- the time until vessel failure, thermal loads at this time and failure conditions are also evaluated (location, mass of corium, etc.) for dry ex-vessel situation. 


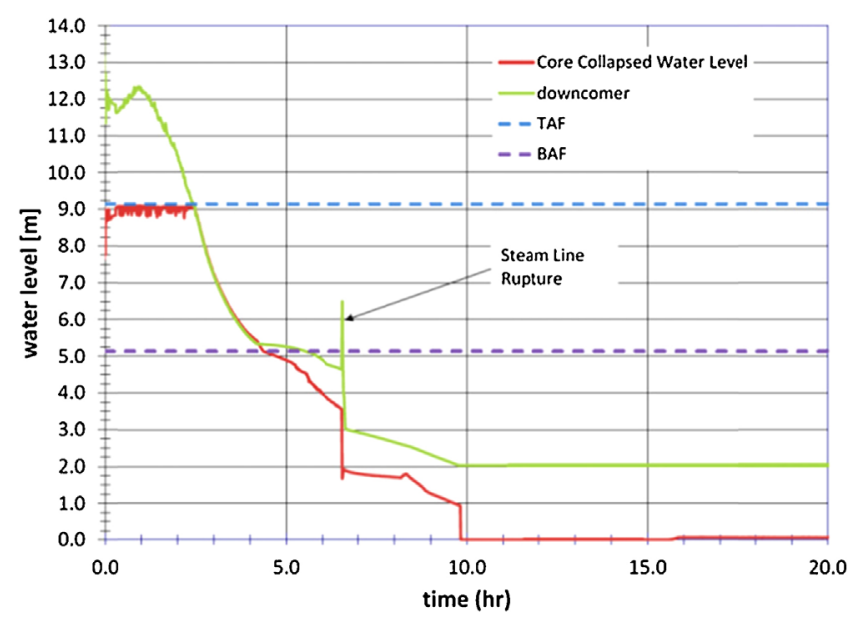

Fig. 1. MELCOR prediction of water level evolution in the reactor core and downcomer regions (Unit 1) [2].

\section{Core degradation and core melt progression}

In the Unit 1 accident, as with all of the affected reactors, following the earthquake, the reactor shutdown was accomplished on March 11, 2011 at 14:46.

According to the MELCOR calculations [2], the loss of cooling water leads to core uncover $\sim 2 \mathrm{~h} 30$ after the reactor shutdown, within a short period of time as shown in Figure 1. From there, the core is not sufficiently cooled and the cladding and fuel heatup follows. When the core temperature reaches between $1000 \mathrm{~K}$ and $1200 \mathrm{~K}$, cladding failure is possible. Indeed, the temperature of the Zircaloy $(\mathrm{Zr})$ cladding can escalate to its melting temperature, which would cause cladding failure and relocation. The $\mathrm{Zr}$ oxidation reaction, once started, leads to fast escalation in fuel temperature. Interaction between fuel, cladding and other structural materials leads to the formation of molten material at temperatures possibly below the individual melting points of the respective materials. This molten material relocates within the core.

In Unit 1, in the absence of adequate core cooling, core degradation leads to a large mass of debris relocating within the lower regions of the core and/or settling on the lower core support plate. Also, molten pools could form within the debris, located in the centre of the core. From the MELCOR results, the appearance of the first liquid corium pool could occur $\sim 4 \mathrm{~h}$ after the reactor shutdown as illustrated in Figure 2. At this time, the water level could be located just above the core support plate.

The kinetics of corium pool growth in a debris bed (see [5]) is governed by two contributions:

- debris melting due to the heat flux at the molten pool boundaries (linked to power dissipation in the corium pool (volume power dissipation $q \sim 0.6 \mathrm{MW} / \mathrm{m}^{3}$ );

- heating and melting of the debris under the effect of residual power in the solid debris.

The molten pool tends to propagate radially, due to heat-flux distribution linked to internal natural convection [9]. Indeed, the lateral heat flux of a corium pool is about

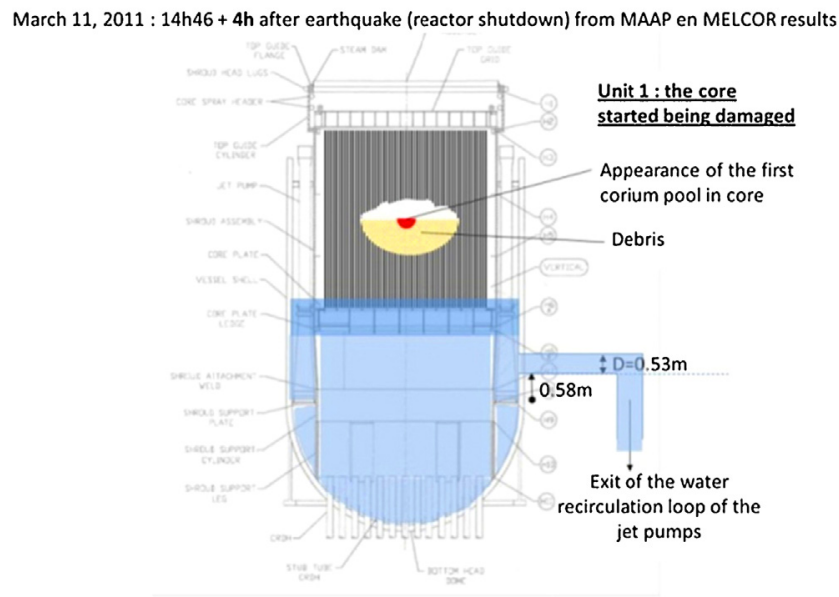

Fig. 2. Illustration of the appearance of the first corium pool in the core: $\sim 4 \mathrm{~h}$ after the reactor shutdown.

one order of magnitude higher than downward heat flux, which limits the axial propagation rate of the corium pool (see Appendix A). Axial melt progression rate is, thus, reduced in comparison with lateral melt progression. In this situation, the corium pool could be supported, during the transient melt progression, by the debris bed and solid relocation in the lower part of the core (Fig. 2). Axial propagation of melt is mainly controlled by debris heat-up and corium relocation in the lower part of the core, but the heat flux from the pool does not contribute significantly to axial progression. Besides, it is important to underline that the downward melt progression is also limited by corium freezing and significant formation of debris from the structure degradation in the lower parts of the core (due to the presence of water and low hydraulic diameter).

Typically, the whole core meltdown process (i.e. $\sim 120 \mathrm{t}$ of oxidic corium from fuel and Zircaloy) could take $\sim 5 \mathrm{~h}$ under dry conditions (after complete core uncovery).

We consider that the corium pool surface was located at the core center i.e. height equal to $\sim 2 \mathrm{~m}$ from the lower support plate (Fig. 2). Due to the tendency of the corium pool to propagate radially, as previously explained, the molten pool could reach the peripheral sub-assemblies before the lower part of the core is molten, as illustrated in Figure 3. When the pool reaches the outer core assemblies, there is no obstacle for the melt to relocate between the core and the shroud ( $\sim 5 \mathrm{~h} 40$ after the reactor shutdown). A relocated melt pool can thus form in this space, which we will call the Core Annulus Pool or CAP (Fig. 4).

The distance between the external core sub-assemblies and the shroud is azimuthally not uniformly distributed, but is of the order of $\sim 0.1$ to $\sim 0.20 \mathrm{~m}$ (mean value: $\sim 0.16 \mathrm{~m})$. A significant proportion of core (20-25 t out of $\sim 120 \mathrm{t}$ ) could relocate between the core and the shroud. The level of corium in this annular space is supposed to reach the same level as the corium pool level in the core, as illustrated in Figure 4. The duration of this sequence is estimated to be $\sim 40 \mathrm{~min}$.

Meanwhile, we assume that the residual water level reaches the core support plate. In the following section, a 




Fig. 3. Illustration of the corium flow in the core annulus pool: $\sim 5 \mathrm{~h} 40$ after the reactor shutdown.



Fig. 4. Illustration of the shroud failure from the core annulus pool: $\sim 6 \mathrm{~h} 40$ after the reactor shutdown.

scenario with the presence of residual water below the core support plate, in the vessel lower head region, is assumed.

\section{Core annulus pool formation}

The corium accumulation duration in the CAP could take $\sim 40$ min. During this period, no water is present on the outside of the shroud. With a small lateral heat flux towards the shroud (order of magnitude ${ }^{1}: \sim 0.03 \mathrm{MW} / \mathrm{m}^{2} ;$ ), the shroud thickness ablated over $40 \mathrm{~min}$ is evaluated to be $\sim 9 \mathrm{~mm}$ out of $38 \mathrm{~mm}$. Besides, the downward heat flux towards the lower support plate is about one order of magnitude lower that the lateral heat flux. During this

\footnotetext{
${ }^{1}$ Assuming that half of the dissipated power in the core $(q)$ will be used to heat the shroud wall: $\varphi \cdot S=q . V / 2$ with: $V$ and $S$ the volume and surface of corium annulus zone.
}

40 min period, the support plate failure (50 mm thickness) is here excluded from the corium relocated in the CAP. Then, when the corium height in the CAP reaches the corium pool level in the core $(\sim 6 \mathrm{~h} 40$ after the reactor shutdown, 40 min after relocation in the CAP), the lateral heat flux towards the shroud (from corium in the core and in the CAP) increases to $\sim 0.3 \mathrm{MW} / \mathrm{m}^{2}$. In this situation, we estimate that the shroud failure could take $\sim 20 \mathrm{~min}$, as illustrated in Figure 4.

We estimate that the shroud failure does not occur before the corium height in the $\mathrm{CAP}$ reaches the corium pool level in the core. We then consider that the shroud fails locally (hot spot) and that relocation in the outer volume consequently leads to a 3D configuration of corium. After shroud failure, the molten corium flows into the Shroud External Annulus (SEA) (space between shroud and vessel) which is occupied by the walls of the recirculation jet pumps and bounded at its lower part by the recirculation jet pump support plate.

At that time, the corium pools in the CAP and in the core form a single pool. From lateral heat flux distribution considerations in the melt pool, we estimate that the corium mass released from the core region towards the shroud external annulus (SEA) is estimated to $\sim 36 \mathrm{t}$.

The focusing effect (if any, linked to metal layer stratification above oxidic corium in the core pool) is not expected to have a significant impact on the time required for the transfer of oxidic material to the SEA. Indeed, in the case of a focusing effect, the metal relocates before the oxidic melt in the external volume which does almost not affect the shroud ablation by the oxydic melt.

\section{Shroud external annulus pool formation (SEA; jet pump area)}

The $\sim 36 \mathrm{t}$ corium mass released from the core region (i.e. core and CAP) towards the shroud external annulus zone (SEA) is expected to occur $\sim 6 \mathrm{~h} 40$ after the reactor shutdown.

We furthermore consider that the duration of corium relocation events is short (a few minutes) in comparison with the whole melting and pool progression time sequence (which takes several hours).

It is worth noticing that an $\sim 13 \mathrm{t}$ water mass could be initially present in the lower part of the SEA area (around the lower part of the jet pumps). We consider that water level is the same level than in the core support plate inside and outside the lower part of the 20 tubes of the jet pumps. Water outside the jet pumps can evaporate from the corium relocation in the SEA which leads to debris formation around the lower part of the jet pumps. We assume that water inside the jet pumps is in connection with the water in the lower head.

The external annulus is bounded at the lower part by the plates supporting the jet pumps. A direct access to the lower head is possible either through the jet pumps $(20 \mathrm{~mm}$ wall thickness) or through the shroud wall $(38 \mathrm{~mm}$ thickness). Nevertheless, this presence of water at high pressure (near to 70 bars; heat flux $\varphi_{\mathrm{CHF}} \sim 7.4 \mathrm{MW} / \mathrm{m}^{2}$ at 


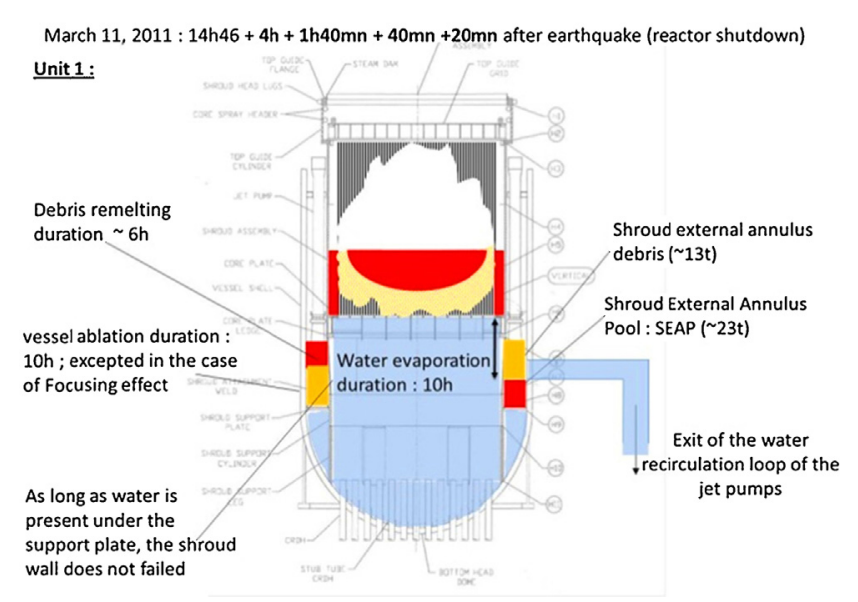

Fig. 5. Illustration of the corium relocation in the SEA: $\sim 6 \mathrm{~h} 40$ after the reactor shutdown.

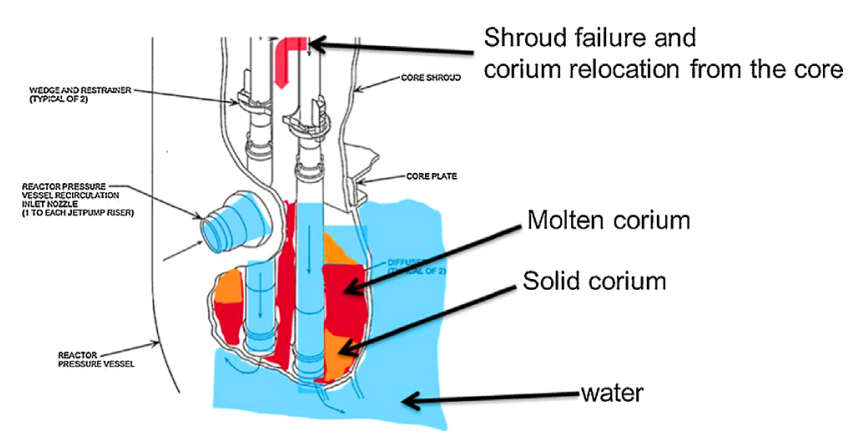

Fig. 6. Zoom of the corium relocation in the SEA: $\sim 6 \mathrm{~h} 40$ after the reactor shutdown.

70 bars $\left.^{2}\right)$ in the lower head and inside the jet pump excludes the wall dry-out.

As illustrated in Figures 5 and 6, corium relocation in residual water in SEA leads to quenching and residual water evaporation. Two situations are possible: complete water evaporation in the SEA or only partial water evaporation.

\subsection{Complete water evaporation in the SEA}

It would lead to a $\sim 13 \mathrm{t}$ solid corium mass (like debris) ${ }^{3}$. The remaining corium mass would be in liquid/dense form i.e. $\sim 23 \mathrm{t}$. The dense/liquid corium height could be just

\footnotetext{
${ }^{2}$ The Critical Heat Flux $(\mathrm{CHF})$ varies as a function of vessel pressure $P$ and enthalpy of water evaporation $L$, as follow: $\varphi_{C H F} \sim \sqrt{\frac{P}{P_{0}} \cdot \frac{L}{L_{0}}}$ with $P_{0}$ the standard pressure $\left(1.013 \times 10^{5} \mathrm{~Pa}\right)$ and $L_{0}$ the evaporation enthalpy at 1 bar $\left(2.2 \times 10^{6} \mathrm{~J} / \mathrm{kg}\right)$. At 70 bars, $L=1.5 \times 10^{6} \mathrm{~J} / \mathrm{kg}$.

If we consider $\varphi_{\mathrm{CHF}} \sim 1.3 \mathrm{MW} / \mathrm{m}^{2}$ at room pressure, $\varphi_{\mathrm{CHF}}$ $\sim 7.4 \mathrm{MW} / \mathrm{m}^{2}$ at 70 bars.

${ }^{3}$ The solid corium mass (like debris) is evaluated from the quench potential of residual water on the basis of the evaporation heat. Here, we assume that water is at saturation temperature and that vapor is not superheated.
}

located below the level of the jet pump recirculation loop, as illustrated in Figure 5. Nevertheless, it cannot be excluded that a small part of liquid corium is released into the jet pump recirculation loop because of the presence of the porosity of the solid corium settled in the SEA and because of 3D effects (local failure of the shroud, local relocation of corium in the SEA space). The re-melting of solid corium (e.g. debris) would then take $\sim 6 \mathrm{~h}$ (see [5]). Besides, heat from the corium pool can be transmitted to the structures i.e. shroud, jet pumps and vessel:

- in the presence of water in the lower head, melting of the vertical shroud and jet pump wall can be excluded (heat flux $\varphi_{\mathrm{CHF}} \sim 7.4 \mathrm{MW} / \mathrm{m}^{2}$ at 70 bars versus $\varphi_{\text {shroud }}$ $\sim 0.04 \mathrm{MW} / \mathrm{m}^{2}$ provided by the corium pool). Also, regarding the $\varphi_{\mathrm{CHF}}$ and $\varphi_{\text {shroud }}$, failure by focusing effect can also be excluded. Besides, regarding the heat flux to the shroud, $\varphi_{\text {shroud }}$, the duration to evaporate water to a level below the support plate in front of the corium pool in the SEA is very long i.e. $\sim 10 \mathrm{~h}$;

- under vessel external dry conditions, melting of the vessel wall would take up to $\sim 10 \mathrm{~h}$. However, if some nonmiscible mass of molten metal relocates on top of the oxidic phase, a risk of early local vessel failure exists due to a focusing effect.

\subsection{Only partial water evaporation}

It is consistent with partial corium quenching and with a limited solid corium mass (like debris) smaller than $13 \mathrm{t}$. A significant corium pool/dense layer could then accumulate from unquenched molten material $(>23 \mathrm{t})$ :

- for this liquid corium mass higher than $23 \mathrm{t}$, the excess corium could potentially be released into the jet pump recirculation loop, as illustrated in Figure 7;

- the remaining water in this area would evaporate at a rate of $\sim 0.2 \mathrm{t} / \mathrm{min}$. As long as water is present, the debris remelting can be excluded;

- under vessel external dry conditions, melting of the vessel would also take $\sim 10 \mathrm{~h}$.

\section{Second melt relocation from the core}

After the first corium relocation from the core region (core and CAP), we estimate that $\sim 40 \mathrm{~min}$ are necessary to continue to propagate the pool in the core before next corium flow through the shroud. But 3D effects may also play a role (e.g., local shroud continuous melting and continuous 3D flow).

The follow-on corium mass released from the core region is evaluated to be $\sim 30 \mathrm{t}$ ( $\sim 7 \mathrm{~h} 20$ after the reactor shutdown namely $\sim 40$ min after the first corium flow, as depicted in Figure 7). Given the presence of liquid/solid corium in the SEA (water can be considered to be evaporated from SEA at this time), we point out that the second corium flow from the core is released into the two recirculation loops of the jet pumps. The recirculation loop dimensions are significant 




Fig. 7. Illustration of the secondary shroud failure from the core annulus pool: $\sim 7 \mathrm{~h} 20$ after the reactor shutdown.

(i.e. $0.53 \mathrm{~m}$ diameter and $\sim 16 \mathrm{~m}$ length down to the pump) which could accumulate a corium mass up to $60 \mathrm{t}$. Also, it can be assumed that water was present in these pipes. The water mass in the recirculation loops is estimated to be $\sim 15$ t. The delay time corresponding:

- to debris quenching (down to $\sim 800 \mathrm{~K}$ );

- to the residual water evaporation;

- to the increase of debris and circuit steel temperatures up to $1700 \mathrm{~K}$ (steel melting temperature);

is $\sim 4 \mathrm{~h}$ at 70 bars (see Appendix B). So, we cannot exclude a failure of the recirculating pipes $\sim 4 \mathrm{~h}$ after corium relocation in these pipes. Thus, a recirculation pipe failure could occur at $\sim 11 \mathrm{~h} 20$ after the reactor shutdown. This is consistent with the decrease of the RPV pressure observed before $\sim 12 \mathrm{~h} \mathrm{[2].}$

Then, the corium from the water recirculation pipe of the jet pumps could be released into the dry well on the basemat, outside the pedestal space, as illustrated in Figure 9 .



Fig. 8. Illustration of the last corium relocation from the core: $\sim 8 \mathrm{~h} 50$ after the reactor shutdown.

\section{Following melt relocation from the core and corium release on the basemat}

After these events, $~ 90$ min would be further necessary to melt the rest of the core under adiabatic conditions. Two situations are emphasized. The first one assumes a flow of residual corium through the core support plate. The second situation corresponds to additional corium relocation through the shroud. Our analysis gives the preference to the second situation because the heat flux to the support plate $\left(\sim 0.01 \mathrm{MW} / \mathrm{m}^{2}\right.$, Ref. [9]) is estimated to be much less than the lateral heat flux $\left(0.4 \mathrm{MW} / \mathrm{m}^{2}\right)$.

It is worth noticing that a thermal failure of instrumentation tubes or guide tubes which are in contact with corium debris or a corium pool (during re-melting of corium) inside the core could plausibly precede core support plate failure. As a conclusion, the tube failure through the core support plate cannot be excluded which would lead to relocating a part of corium from the core.

Nevertheless, the lateral relocation (through the shroud) is the conjecture privileged in our scenario analysis. Some part of the remaining corium mass in the core region $(\sim 54 \mathrm{t})$ could potentially relocate to the SEA, $\sim 9 \mathrm{~h}$ after the reactor shutdown.

As regards the corium pool in the core, the lower and upper crust thicknesses are evaluated to be $\sim 8 \mathrm{~cm}$ and $\sim 4 \mathrm{~cm}$, respectively. These crust thicknesses correspond to $\sim 10 \mathrm{t}$ of solid corium out of $54 \mathrm{t}$ in the core, as illustrated in Figure 8. The liquid corium part (i.e. 44 t) could flow from the core in the water recirculation loop of the jet pumps (via the SEA). The corium part in crust form is assumed to remain in the core.

Following the failure of the water recirculation loop of the jet pumps ( $\sim 11 \mathrm{~h} 20$ after the reactor shutdown), we consider that a part of $\sim 90 \mathrm{t}$ of corium can be relocated on the dry well basemat, as shown in Figure 9. From there, it should be necessary to study the MCCI outside the pedestal space. 


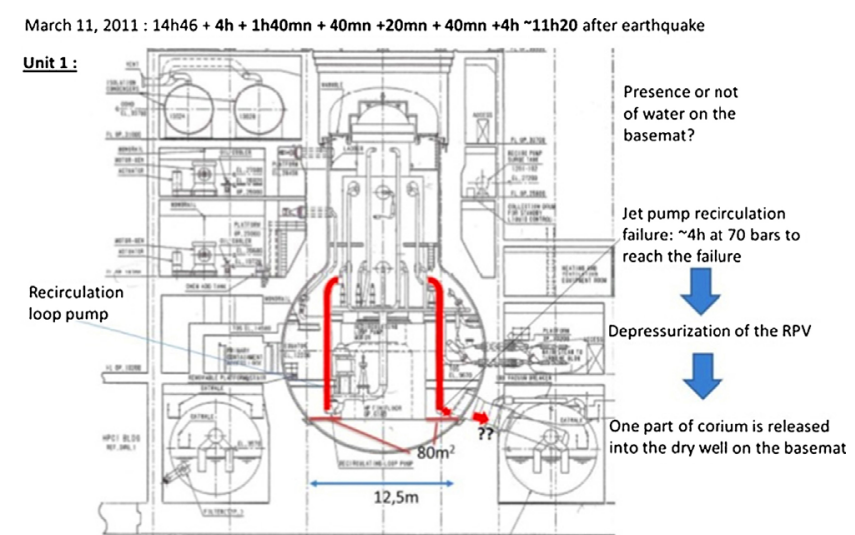

Fig. 9. Illustration of the jet pump recirculation failure from liquid corium settled inside: $\sim 11$ h 20 after the reactor shutdown.

\section{Conclusion}

This study presents an analysis of the in-vessel melt progression in the Unit 1 of the Fukushima Dai-ichi nuclear power plant. Not excluding axial melt progression and core support plate failure, this work focuses on the sequence based on a lateral progression of the molten fuel. The corium could potentially flow through the shroud well before axial draining through the support plate. This scenario leads to the corium accumulation in the core periphery and, from there, in the shroud external annulus, with the jet pumps, before potentially penetrating in the jet pump recirculation loops.

The lateral progression of the molten fuel assumed in this study have been carried out relying on major measurements in the plant during the accident, such as core water level, RPV pressure and PCV pressure. Due to uncertainties caused by the limited information including measurements and physical comprehension, several accident scenarios can reproduce relatively well the measured values. In the frame of the BSAF project, the lateral progression of the molten fuel through the shroud was also predicted by two participants releasing corium in the lateral lower part of the vessel. The other participants predict an axial draining through the support plate.

\section{Appendix A}

The analytic expressions for lateral local heat flux distribution $(\varphi)$ were obtained from BALI results [9] which were qualified for turbulent boundary layer regime and top cooled cavity, in 3D geometry (hemisphere), as written hereafter:

$$
\begin{aligned}
& \frac{\varphi}{\varphi \max }=\sin (\theta)^{1 / 3\left(\frac{1-\cos (\theta)}{k^{H}}\right)^{4 / 3}} \text { for } \theta<\operatorname{arcos}(1-k H / R) \\
& \frac{\varphi}{\varphi \max }=\sin (\theta)^{1 / 3} \text { for } \operatorname{arcos}(1-k H / R)<\theta<\operatorname{arcos}(1-H / R)
\end{aligned}
$$

with $k=0.60$ and 0.70 for $H / R=0.25$ and 1.0 , respectively with $R, H$ and $\theta$ the radius, the height and the local inclination of the corium pool.

The lateral local heat flux distribution is presented just below.

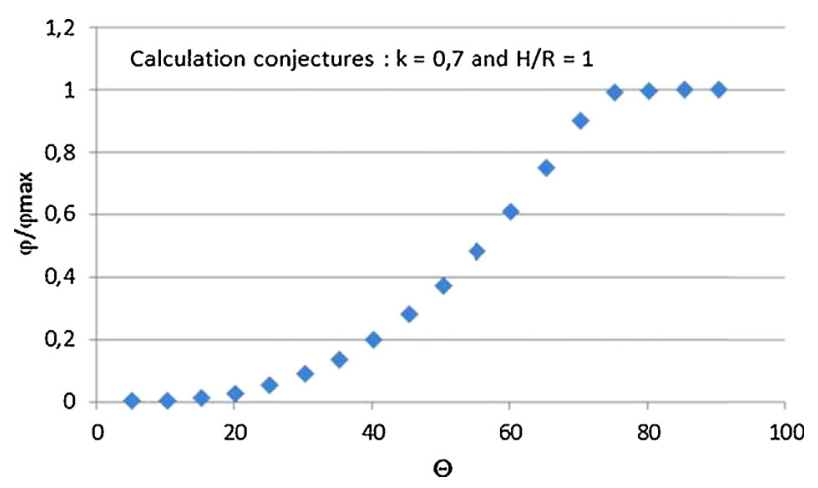

Fig. A.1 The lateral local heat flux distribution for a oxide corium pool from BALI experiments.

\section{Appendix B: Corium relocation in a steel pipe in the presence of water}

Objective: evaluation of the failure time of a steel pipe when corium is release inside in the presence of water

Analysis: the corium transfer in a pipe in the presence of water can be described by an energy balance as followed:

$$
\begin{aligned}
& M_{\text {corium }}\left(L_{f}+C_{p}\left(T_{i}-T_{f}\right)\right)+\frac{M_{\text {corium }} \cdot q_{\mathrm{vol}}}{\rho_{\text {corium }}} \cdot \tau= \\
& M_{\text {water }} \cdot L_{\text {water }}+M_{\text {steel }} \cdot\left(C_{\mathrm{p}}\left(T_{\text {melting-steel }}-T_{f}\right)\right)+ \\
& M_{\text {corium }} \cdot\left(C_{\mathrm{p}}\left(T_{\text {melting-steel }}-T_{f}\right)\right)+\varphi_{\text {lost }} \cdot \tau \cdot S_{\text {pipe }}
\end{aligned}
$$

with

$M_{\text {corium }} \quad$ the corium mass in the pipe

$M_{\text {steel }} \quad$ the steel mass of the pipe

$L_{\mathrm{f}} \quad$ latent melting heat of corium

$\left(2.8 \times 10^{5} \mathrm{~J} / \mathrm{kg}\right)$

$C_{\mathrm{p}} \quad$ specific heat $(517 \mathrm{~J} / \mathrm{kg} / \mathrm{K}$ for corium and $600 \mathrm{~J} / \mathrm{kg} / \mathrm{K}$ for steel)

$T_{\mathrm{f}} \quad$ debris temperature $(800 \mathrm{~K})$

$T_{\mathrm{i}} \quad$ initial temperature $(2800 \mathrm{~K})$

$T_{\text {melting steel }}$ steel melting temperature $(1700 \mathrm{~K})$

$q_{\mathrm{vol}}$ the volumetric core power dissipation (i.e. $0.55 \mathrm{MW} / \mathrm{m}^{3}$ for the Unit 1)

$\tau \quad$ the failure characteristic time

$M_{\text {water }} \quad$ the water mass

$L_{\text {water }} \quad$ the water evaporation heat $\left(1.5 \times 10^{6} \mathrm{~J} / \mathrm{kg}\right.$ at 70 bars)

$\varphi_{\text {lost }} \quad$ the lost heat flux

$\mathrm{S}_{\text {pipe }} \quad$ the pipe section 
As presented in the main text, it can be assumed that $30 \mathrm{t}$ of corium are released in two steel pipes with a $0.58 \mathrm{~m}$ diameter (and a $16 \mathrm{~m}$ length) filled with $15 \mathrm{t}$ water. By neglecting the lost energy (i.e. the last term), the steel failure time can be evaluated i.e. $\sim 10 \mathrm{~h}$.

\section{References}

1. N. Watanabe et al., Review of five investigation committee's reports on the Fukushima Dai-ichi nuclear power plant severe accident: focusing on accident progression and causes, J. Nucl. Sci. Technol. 52, 41 (2015)

2. R. Ganntt, D. Kalinich, J. Cardoni, J. Phillips, A. Goldmann, S. Pickering, M. Francis, K. Robb, L. Ott, D. Wang, C. Smith, S. St. Germain, D. Schwieder, S. Phelan, Fukushima Daiichi Accident Study (Status as of April 2012), Sandia Report Sand 2012-6173, Unlimited Release Printed 2012

3. H. Bonneville, A. Luciani, Simulation of the core degradation phase of the Fukushima accidents using the ASTEC code, Nucl. Eng. Des. 272, 261 (2014)
4. H. Esmaili, M. Khatib-Rahbar, Analysis of In-Vessel Retention and Ex-Vessel Fuel Coolant Interaction for AP1000, NUREG/CR. 6849 ERTNRC O4. 2OI, 2004

5. J.M. Seiler, B. Tourniaire, A phenomenological analysis of melt progression in the lower head of a pressurized water reactor, Nucl. Eng. Des. 268, 87 (2014)

6. R. Le Tellier, L. Saas, F. Payot, Phenomenological analyses of corium propagation in LWRs: the PROCOR software platform, in ERMSAR 2015 Marseille, France, 24-26 March 2015 (2015)

7. I. Sato, Experimental program for the understanding of Fukushima-Daïshi phenomena, in PLINIUS 2 seminar Marseille, 2014 (2014)

8. M. Pellegrini, K. Dolganov, L.E. Herranz Puebla, H. Bonneville, D. Luxat, M. Sonnenkalb, S. Band, F. Nagase, J.H. Song, J.H. Park, T.W. Kim, S.I. Kim, R.O. Gauntt, L. Fernandez Moguel, F. Payot, H. Hoshi, Y. Nishi, Benchmark Study of the Accident at the Fukushima Daiichi Nuclear Power Plant Phase I, Final Report, OECD/NEA BSAF project, 2015

9. J.M. Bonnet, An integral model for the calculation of heat flux distribution in a pool with internal heat generation, in Nureth 7 Conference Saratoga Springs NY. USA, September 10-15 1995 (1995)

Cite this article as: Frédéric Payot and Jean-Marie Seiler, Possible in-vessel corium progression way in the Unit 1 of Fukushima Dai-ichi nuclear power plant using a phenomenological analysis, EPJ Nuclear Sci. Technol. 1, 7 (2015) 